\title{
Evaluation of the knowledge, attitudes and practices of diabetic patients in a tertiary care hospital in Central India
}

\author{
Tejaswi P. ${ }^{1}$, Dhakre S. ${ }^{2}$, Reddy P. ${ }^{3}$, Goyal C. ${ }^{4}$ \\ ${ }^{1}$ Dr. Prerna Tejaswi, Third Year PG Resident, Department of Pharmacology, Sri Aurobindo Medical College and \\ Postgraduate Institute, Indore (M.P.), ${ }^{2}$ Dr. Dhakre S, Assistant Professor, Department of Pharmacology, Shri Dev Suman \\ Subharti Medical College, Dehradun, Uttarakhand, ${ }^{3}$ Dr. Reddy P, Associate Professor, ${ }^{4}$ Dr. Goyal C, Professor and Head, \\ above two authors attached with Department of Pharmacology, Sri Aurobindo Medical College and Postgraduate \\ Institute, Indore, M.P, India.
}

Address for Correspondence: Dr. Prerna Tejaswi, Dr. Arbind Kumar Road,Bengali Tola, Samastipur, Bihar. Email Id- prernatejaswi@yahoo.in

\begin{abstract}
Introduction: A right approach to diabetes can reduce morbidity, mortality, and the burden of costs among diabetics. It is important to gather information about the knowledge, attitudes, and practices of people with diabetes to develop effective health education and diabetes control awareness programs. Objectives: To assess the knowledge, attitudes, and practices of patients suffering from type 2 diabetes. Materials and Methods: A prospective observational study was conducted with 100 type 2 diabetics of either gender, who were admitted in the general medicine ward and consented to participate in the study. A suitable 26-item semi-structured questionnaire was designed, with "Yes" and "No" as response options. Each appropriate answer was assigned a score of 1. Results: In total, 56\%, 42\%, and 2\% of the subjects showed a good, moderate and poor knowledge grades, respectively. Regarding attitude, $64 \%$ and 36\% of the patients exhibited good and poor grades, respectively. Only $31 \%$ of the participants achieved a good practice grade, $59 \%$ secured average while $10 \%$ of them got poor grades. The overall KAP results of $43 \%$ of the patients was good, $55 \%$ scored average whereas $2 \%$ scored poor grades. Assessment of the overall KAP grade with the demographic variables showed that there is a statistically significant association of the grades with the education, occupation, and socioeconomic status $(\mathrm{P}<0.05)$. Conclusion: It is necessary to provide appropriate health education and individual counseling to ensure that each patient with diabetes has sufficient information and that he/she is motivated to lead a better life.
\end{abstract}

Keywords: Diabetes mellitus, KAP, Diabetes Control, Awareness

\section{Introduction}

Diabetes Mellitus is linked to high rates of morbidity and mortality [1]. The global prevalence of diabetes in adults was $6.4 \%$ in 2010 , and it is expected to increase to $7.7 \%$ by 2030 [2]. India is considered as the diabetes capital of the world [3].

Being a developing nation, India has a huge economic burden to overcome to control the morbidity and mortality associated with diabetes. In 2010, it was reported that only $19 \%$ of the Indian population was covered by state and central government sponsored health insurance policies, which indicates that the burden of health care costs directly falls upon patients

Manuscript received: $30^{\text {th }}$ December 2017

Reviewed: $9^{\text {th }}$ January 2018

Author Corrected: $18^{\text {th }}$ January 2018

Accepted for Publication: $23^{\text {rd }}$ January 2018 and their families [4]. Since a majority of the diabetics fall within 45-64 years age group, it can threaten the earning abilities and financial productivity of the country [5]. Awareness of and a right approach to diabetes can significantly reduce the morbidity and mortality, and can cut down the burden of health care costs among diabetics.

The acquisition of information about the Knowledge, Attitudes, and Practices (KAP) of diabetic population is therefore important for developing efficient health education and diabetes control awareness programs.

\section{Objectives}

To assess the knowledge, attitudes, and practices of patients suffering from type 2 diabetes. 


\section{Methodology}

Study Area- Department of Pharmacology, Sri Aurobindo Medical College and Postgraduate Institute, Indore (M.P.)

Study Population- Patients admitted in our hospital with type 2 diabetes during the study period

Study Duration- Study was conducted from February 2015 to January 2016.

Sample Size- Considering the worldwide prevalence of diabetes as $6.4 \%$, we calculated the sample size with a $5 \%$ margin of error [2]. The resultant sample size was 92; hence, we recruited 100 patients for the study.

Study Design- Prospective, non-randomized, observational study.

\section{Inclusion Criteria}

- Patients aged above 20 years, of either sex.

- Patients suffering from type 2 diabetes mellitus, with or without co-morbidities.

- Patients willing to provide voluntary written informed consent.

\section{Exclusion Criteria}

- Patients aged below 20 years.

- Patients suffering from type 1 diabetes mellitus or gestational diabetes.

- Patients not willing to provide voluntary written informed consent.

Procedure- The study was explained to the patients in detail in the language understood by them. After receiving their verbal consent to participate, their voluntary written informed consent was acquired prior to getting the questionnaire filled.

We included 100 patients who were admitted in the general medicine ward for type 2 diabetes mellitus and were willing and consented to participate in the study. The patients' age varied, and the sample included patients of both genders. A suitable semi-structured questionnaire was designed based on similar validated studies [6-10].The designed questionnaire was developed in English, translated to the local vernacular language Hindi, and retranslated to English. Prior to the commencement of the main study, the questionnaire was pretested on 5 patients to examine its suitability and validity. There was a total of 26 questions in the questionnaire, with 14, 4, and 8 items on knowledge (Table 1), attitude (Table 2), and practice (Table 3), respectively. Response options were "Yes" and "No," and a score of 1 point was awarded for each appropriate answer.

Table-1: Questionnaire for assessing knowledge.

\begin{tabular}{|c|c|c|}
\hline Sr No & Knowledge questions & \% of patients with appropriate answers \\
\hline 1 & Do you know you are suffering from diabetes? & $100 \%$ \\
\hline 2 & Do you know that more individuals are diagnosed with \\
diabetes nowadays? & $86 \%$ \\
\hline 3 & Do you know the normal range of blood glucose level? & $38 \%$ \\
\hline 4 & Does diabetes run in families? & $46 \%$ \\
\hline 5 & Is obesity a risk factor for the development of diabetes? & $70 \%$ \\
\hline 6 & Are you aware of hypoglycaemia and its symptoms? & $97 \%$ \\
\hline 7 & Do you know that diabetes can affect your eyes? & $55 \%$ \\
\hline 8 & Do you know that diabetes can affect your kidneys? & $62 \%$ \\
\hline 9 & Are you aware of diabetic foot? & $94 \%$ \\
\hline 10 & Is diabetes a contagious disease? & $96 \%$ \\
\hline 11 & Does exercise and physical activity affect blood sugar levels? & $86 \%$ \\
\hline 12 & Is a diet with limited carbohydrates beneficial in diabetes? & $99 \%$ \\
\hline 13 & Can diabetes be permanently cured? & $84 \%$ \\
\hline 14 & Should you stop taking medication if your blood glucose level & $70 \%$ \\
\hline
\end{tabular}


Table-2: Questionnaire for assessing attitudes.

\begin{tabular}{|c|c|c|}
\hline Sr No & Attitude questions & \% of patients with appropriate answers \\
\hline 1. & Do you think it is necessary to monitor blood glucose \\
levels regularly? & $98 \%$ \\
\hline 2. & Do you believe in following a controlled diet? & $94 \%$ \\
\hline 3 & Are you willing to exercise daily? & $49 \%$ \\
\hline 4 & Are you willing to take your medicines regularly? & $69 \%$ \\
\hline
\end{tabular}

Table-3: Questionnaire for assessing practices.

\begin{tabular}{|c|c|c|}
\hline Sr. No. & Practice questions & \% of patients with appropriate answers \\
\hline 1. & Do you visit the doctor for regular check-ups? & $98 \%$ \\
\hline 2. & Do you have a glucometer? & $19 \%$ \\
\hline 3. & Do you check your blood sugar at least once a month? & $72 \%$ \\
\hline 4. & Do you include fruits in your diet every day? & $74 \%$ \\
\hline 5. & Does your meal include green leafy vegetables and salad? & $95 \%$ \\
\hline 6. & Do you go for eye check-ups at least every six months? & $41 \%$ \\
\hline 7. & Do you check your feet daily for any wound or injury? & $55 \%$ \\
\hline 8. & Do you take your medicines as prescribed? & $98 \%$ \\
\hline
\end{tabular}

Data Collection Method- The predesigned questionnaire was used for collecting data.

Statistical Analysis- The associations of the demographic variables with the knowledge, practice, and attitude levels were calculated using the Pearson chi-square test. $\mathrm{P}<0.05$ was considered as statistically significant.

Financial Inputs and Funding- The cost of the study was completely borne by the researchers. As this was a survey, no additional test/procedure or investigation was conducted as a part of the study. Hence, there was no financial burden on the patient or on the institution.

Ethical Considerations- The present study protocol was approved by our Institutional Ethics Committee before the commencement of the study. Additionally, prior to the collection of any information from the patients, their written voluntary informed consent was obtained. Only the data on the study variables were analyzed, and all the personal information of the patients was kept confidential.

\section{Results}

Majority of the patients belonged to the 51-60 years age group (40\%), followed by the 41-50 years group (36\%). Their mean agewas $54.96 \pm 8.88$ years. Majority of the patients were males comprising of $56 \%$; rest $44 \%$ were females. The male: female ratio was $1.27: 1$. Further, $19 \%$ of the patients were illiterate, majority of them had a poor level of education (up to primary or secondary schooling), while only $32 \%$ of them had completed their graduation or post-graduation. This pattern was observed because our institute generally caters to patients from the poor socioeconomic strata. With reference to occupation, $21 \%$ patients were housewives, $11 \%$ were engaged in farming, $17 \%$ were engaged in business, $6 \%$ were laborers, and majority of the patients were engaged in a service (45\%). Further, $8 \%$ of the patients had a poor socioeconomic status, $34 \%$ belonged to the lower class, majority of them (56\%) belonged to the middle class, and only $2 \%$ of them were in the upper class.

Knowledge of Diabetes (Table 4)- The total possible score of 14 on the knowledge scale was classified as good (11-14), average (6-10), and poor grades (0-5). Majority of the subjects (56\%) exhibited a good grade of knowledge scores, $42 \%$ had an average knowledge grade, and $2 \%$ had a poor knowledge grade. All patients reported that they were aware of their diabetes diagnosis. Most of the patients (86\%) agreed that more people were being affected by diabetes. However, only $38 \%$ of the subjects had sufficient knowledge about normal blood sugar levels. Majority of the patients (54\%) were unaware about the genetic predisposition to diabetes, but $70 \%$ of the patients knew that obesity was a major risk factor for the development of diabetes. A total of $97 \%$ of our patients were aware of hypoglycaemia and its symptoms. Further, 
Original Research Article

$55 \%$ and $62 \%$ of the subjects were aware that diabetes could adversely affect their eyes and kidneys, respectively. Most of the patients (94\%) knew about diabetic foot. As many as $96 \%$ of the individuals were aware that diabetes mellitus is not a contagious disease. A great majority of the subjects (86\%) also knew that exercise and physical activity had a significant impact on the blood glucose level. Approximately all patients (99\%) were aware that a diet low in carbohydrates was beneficial for the control of diabetes, and $84 \%$ of the patients knew that diabetes can be controlled but not cured. Finally, $70 \%$ of the patients were aware that medications should not be stopped completely even when blood sugar is normalized, in contrast to $30 \%$ of those who thought otherwise.

Table-4: Association of demographic variables with knowledge grades $(\mathrm{N}=100)$.

\begin{tabular}{|c|c|c|c|c|c|c|}
\hline \multirow[t]{2}{*}{ Demographic Variables } & \multicolumn{3}{|c|}{ Knowledge Grades } & \multirow[t]{2}{*}{ Total } & \multirow[t]{2}{*}{$\chi^{2}$ values } & \multirow[t]{2}{*}{ P value } \\
\hline & $\begin{array}{l}\text { Poor } \\
(0-5)\end{array}$ & $\begin{array}{c}\text { Average } \\
(6-10)\end{array}$ & $\begin{array}{c}\text { Good } \\
(11-14)\end{array}$ & & & \\
\hline Age: & & & & & \multirow{6}{*}{$9.600, \mathrm{DF}=8$} & \multirow{6}{*}{0.294} \\
\hline $35-40$ years & 0 & 1 & 1 & 2 & & \\
\hline $41-50$ years & 1 & 14 & 21 & 36 & & \\
\hline $51-60$ years & 0 & 14 & 26 & 40 & & \\
\hline $61-70$ years & 1 & 7 & 7 & 15 & & \\
\hline$>70$ years & 0 & 6 & 1 & 7 & & \\
\hline \multicolumn{7}{|l|}{ Gender: } \\
\hline Female & 2 & 22 & 20 & 44 & \multirow{2}{*}{$5.303, \mathrm{DF}=2$} & \multirow{2}{*}{0.071} \\
\hline Male & 0 & 20 & 36 & 56 & & \\
\hline Education: & & & & & \multirow{6}{*}{ 45.208, $\mathrm{DF}=8$} & \multirow{6}{*}{$0.000^{*}$} \\
\hline Illiterate & 2 & 16 & 1 & 19 & & \\
\hline Primary education & 0 & 14 & 11 & 25 & & \\
\hline Secondary education & 0 & 10 & 14 & 24 & & \\
\hline Graduate & 0 & 2 & 22 & 24 & & \\
\hline Post graduate & 0 & 0 & 8 & 8 & & \\
\hline \multicolumn{7}{|l|}{ Occupation: } \\
\hline Business & 0 & 5 & 12 & 17 & \multirow{5}{*}{ 21.387, $\mathrm{DF}=8$} & \multirow{5}{*}{$0.006^{*}$} \\
\hline Farming & 0 & 6 & 5 & 11 & & \\
\hline Housewife & 1 & 12 & 8 & 21 & & \\
\hline Laborer & 1 & 5 & 0 & 6 & & \\
\hline Service & 0 & 14 & 31 & 45 & & \\
\hline \multicolumn{7}{|l|}{ SES: } \\
\hline Poor class & 1 & 6 & 1 & 8 & \multirow{4}{*}{$28.487, \mathrm{DF}=6$} & \multirow{4}{*}{$0.000^{*}$} \\
\hline Lower class & 0 & 23 & 11 & 34 & & \\
\hline Middle Class & 1 & 13 & 42 & 56 & & \\
\hline Upper Class & 0 & 0 & 2 & 2 & & \\
\hline
\end{tabular}

N-Sample size, *- P value significant, DF- Degrees of Freedom, SES- Socioeconomic Status.

A comparison of knowledge level based on demographic variables revealed a statistically significant association between education, occupation, and socioeconomic status $(\mathrm{P}<0.05)$. Thus, these three demographic variables impact the knowledge score of the patients. However, no statistically significant association was seen with reference to age and gender $(\mathrm{P}>0.05)$.

Attitude towards Diabetes (Table 5)- Out of the total possible score of 4, scores of 0-2 were classified as poor and those of 3-4 were classified as good grade. Majority (64\%) of the patients exhibited a good attitude grade, while $36 \%$ exhibited a poor attitude grade. Approximately all patients (98\%) thought that the regular monitoring of blood glucose levels was necessary. Only $6 \%$ of the subjects did not want to follow a controlled diet plan, whereas the remaining $94 \%$ believed in following a diet plan. In this study, half (50\%) of the subjects had a negative attitude towards exercise. Finally, majority of patients $(69 \%)$ were found to be willing to take their medications regularly. 
Table-5: Association of demographic variables with attitude grades $(\mathrm{N}=100)$.

\begin{tabular}{|c|c|c|c|c|c|}
\hline \multirow[t]{2}{*}{ Demographic Variables } & \multicolumn{2}{|c|}{ Attitude Grades } & \multirow[t]{2}{*}{ Total } & \multirow[t]{2}{*}{$\chi^{2}$ values } & \multirow[t]{2}{*}{ P value } \\
\hline & Poor (0-2) & Good (3-4) & & & \\
\hline Age: & & & & \multirow{6}{*}{$0.630, \mathrm{DF}=4$} & \multirow{6}{*}{0.960} \\
\hline $35-40$ years & 1 & 1 & 2 & & \\
\hline $41-50$ years & 13 & 23 & 36 & & \\
\hline 51-60 years & 13 & 27 & 40 & & \\
\hline $61-70$ years & 6 & 9 & 15 & & \\
\hline$>70$ years & 3 & 4 & 7 & & \\
\hline \multicolumn{6}{|l|}{ Gender: } \\
\hline Female & 14 & 30 & 44 & $0.596, \mathrm{DF}=1$ & 0.440 \\
\hline Male & 22 & 34 & 56 & & \\
\hline \multicolumn{6}{|l|}{ Education: } \\
\hline Illiterate & 11 & 8 & 19 & \multirow{5}{*}{$9.035, \mathrm{DF}=4$} & \multirow{5}{*}{0.060} \\
\hline Primary education & 11 & 14 & 25 & & \\
\hline Secondary education & 8 & 16 & 24 & & \\
\hline Graduate & 4 & 20 & 24 & & \\
\hline Postgraduate & 2 & 6 & 8 & & \\
\hline \multicolumn{6}{|l|}{ Occupation: } \\
\hline Business & 5 & 12 & 17 & \multirow{5}{*}{$2.676, \mathrm{DF}=4$} & \multirow{5}{*}{0.613} \\
\hline Farming & 6 & 5 & 11 & & \\
\hline Housewife & 7 & 14 & 21 & & \\
\hline Laborer & 3 & 3 & 6 & & \\
\hline Service & 15 & 30 & 45 & & \\
\hline \multicolumn{6}{|l|}{ SES: } \\
\hline Poor class & 6 & 2 & 8 & \multirow{4}{*}{$10.974, \mathrm{DF}=3$} & \multirow{4}{*}{$0.012 *$} \\
\hline Lower class & 13 & 21 & 34 & & \\
\hline Middle Class & 15 & 41 & 56 & & \\
\hline Upper Class & 2 & 0 & 2 & & \\
\hline
\end{tabular}

N- Sample size, *- P value significant, DF- Degrees of Freedom, SES- Socioeconomic Status.

An analysis of attitude grades with reference to demographic variables revealed a statistically significant association between attitude and the socioeconomic status of subjects $(\mathrm{P}<0.05)$. Thus, socioeconomic status impacts the attitudes toward diabetes. However, no statistically significant association was observed with reference to age, gender, education, and occupation $(\mathrm{P}>0.05)$.

Practices among Diabetics (Table 6)-Out of the total possible score of 8, scores ranging from 0-3 were classified as poor, those of 4-6 were classified as average, and those of 7-8were classified as good grades. Majority (59\%) of the patients exhibited average practice grade followed by $31 \%$ who had a good practice grade, and the rest $10 \%$ who had a poor practice grade. Almost all the patients in the present study (98\%) visited the doctor regularly. Most of them (72\%) reported that they monitored their blood sugar levels regularly; however, only $19 \%$ of them possessed a personal glucometer. Majority of the patients included fruits (74\%) and green vegetables (95\%) in their daily meals. Further, only $41 \%$ of the patients reported having regular eye check-ups (at least every six months) while $55 \%$ of the patients monitored their feet daily for any injury. Almost all the subjects (98\%) were compliant with the prescribed medications.

Assessment of practice grades with the demographic variables revealed a statistically significant association of practice grades with the education, occupation, and socioeconomic status of the patients $(\mathrm{P}<0.05)$. Thus, these three demographic variables were found to influence the practice score of the patients. However, no statistically significant association was observed with reference to age and gender $(\mathrm{P}>0.05)$. 
Table-6: Association of demographic variables with practice grades $(\mathrm{N}=100)$.

\begin{tabular}{|c|c|c|c|c|c|c|}
\hline \multirow[t]{2}{*}{ Demographic Variables } & \multicolumn{3}{|c|}{ Practice Grades } & \multirow[t]{2}{*}{ Total } & \multirow[t]{2}{*}{$\chi^{2}$ values } & \multirow[t]{2}{*}{ P value } \\
\hline & $\begin{array}{l}\text { Poor } \\
(0-3)\end{array}$ & $\begin{array}{c}\text { Average } \\
(4-6)\end{array}$ & $\begin{array}{l}\text { Good } \\
(7-8)\end{array}$ & & & \\
\hline Age: & & & & & \multirow{6}{*}{$10.508, \mathrm{DF}=8$} & \multirow{6}{*}{0.231} \\
\hline $35-40$ years & 1 & 1 & 0 & 2 & & \\
\hline $41-50$ years & 4 & 19 & 13 & 36 & & \\
\hline $51-60$ years & 1 & 27 & 12 & 40 & & \\
\hline $61-70$ years & 2 & 8 & 5 & 15 & & \\
\hline$>70$ years & 2 & 4 & 1 & 7 & & \\
\hline \multicolumn{7}{|l|}{ Gender: } \\
\hline Female & 4 & 30 & 10 & 44 & \multirow[t]{2}{*}{$2.922, \mathrm{DF}=2$} & \multirow[t]{2}{*}{0.232} \\
\hline Male & 6 & 29 & 21 & 56 & & \\
\hline \multicolumn{7}{|l|}{ Education: } \\
\hline Illiterate & 4 & 15 & 0 & 19 & \multirow{5}{*}{ 26.306, $\mathrm{DF}=8$} & \multirow{5}{*}{$0.001 *$} \\
\hline Primary education & 5 & 16 & 4 & 25 & & \\
\hline Secondary education & 1 & 14 & 9 & 24 & & \\
\hline Graduate & 0 & 11 & 13 & 24 & & \\
\hline Postgraduate & 0 & 3 & 5 & 8 & & \\
\hline \multicolumn{7}{|l|}{ Occupation: } \\
\hline Business & 1 & 7 & 9 & 17 & \multirow{5}{*}{$17.350, \mathrm{DF}=8$} & \multirow{5}{*}{$0.027^{*}$} \\
\hline Farming & 3 & 5 & 3 & 11 & & \\
\hline Housewife & 2 & 16 & 3 & 21 & & \\
\hline Laborer & 2 & 4 & 0 & 6 & & \\
\hline Service & 2 & 27 & 16 & 45 & & \\
\hline \multicolumn{7}{|l|}{ SES: } \\
\hline Poor class & 1 & 7 & 0 & 1 & \multirow{4}{*}{$19.764, \mathrm{DF}=6$} & \multirow{4}{*}{$0.003 *$} \\
\hline Lower class & 5 & 26 & 3 & 5 & & \\
\hline Middle Class & 4 & 25 & 27 & 4 & & \\
\hline Upper Class & 0 & 1 & 1 & 0 & & \\
\hline
\end{tabular}

N- Sample size, *- P value significant, DF- Degrees of Freedom, SES- Socioeconomic Status.

Overall Knowledge, Attitudes, and Practices (KAP) Grades (Table 7)- Out of the possible overall KAP grades of 26, score of 0-10 were classified as poor, those of 11-20 were classified as average, and those of 21-26 were classified as good grades.

Only $2 \%$ of the patients had poor overall KAP grade, whereas $55 \%$ and $43 \%$ had average and good KAP grades respectively.

An evaluation of overall KAP scores with the demographic variables revealed a statistically significant association of overall KAP grades with the education, occupation, and socioeconomic status of the patients $(\mathrm{P}<0.05)$.

Thus, these three demographic variables were found to influence the overall KAP score of the patients. However, no statistically significant association was observed in terms of age and gender $(\mathrm{P}>0.05)$. 
Original Research Article

Table-7: Association of demographic variables with overall KAP grades $(\mathrm{N}=100)$.

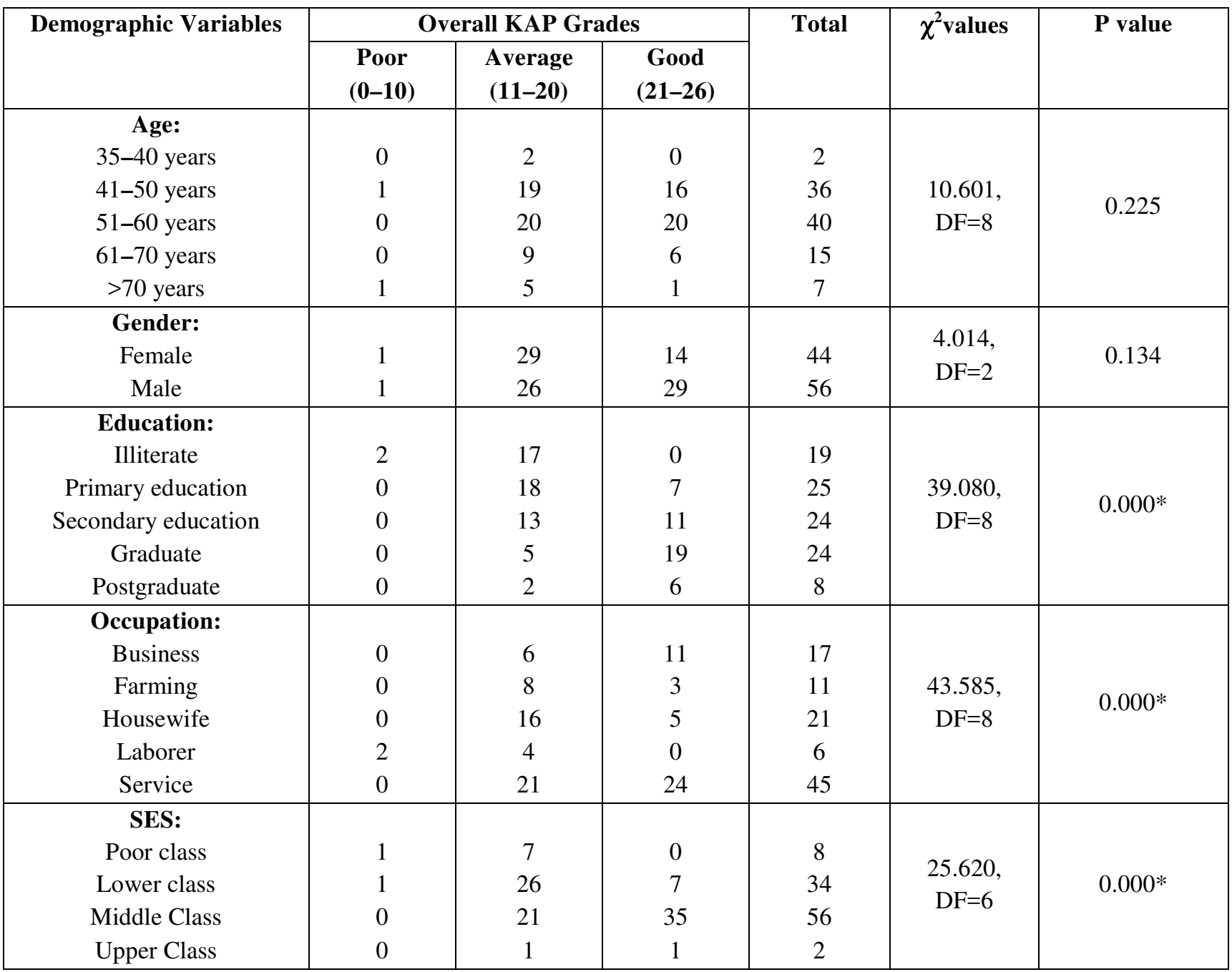

N- Sample size, *- P value significant, DF- Degrees of Freedom, SES- Socioeconomic Status

\section{Discussion}

We conducted this survey to understand the status of diabetes-related knowledge, attitudes, and practices in a group of diabetic subjects. KAP study results usually vary owing to the demographic characteristics, questionnaire format, and data analysis used in the study. The present findings suggest that majority $(56 \%)$ of the patients had good knowledge of diabetes, but they lacked information about specific factors related to their condition. Although considerable time had passed since they were diagnosed with diabetes, and most checked their blood glucose level regularly, majority of them $(62 \%)$ were unaware of the normal blood glucose values. In other words, only $38 \%$ of our patients were aware of the normal level of blood sugar, which is similar to the findings reported by Al Bhimani et al. in their study on knowledge and practices related to type 2 diabetes in Omani patients [10]. However, in a similar KAP study conducted by Rathod et al. on the population of Waghodia in Gujarat, the knowledge related to blood sugar level was very high $(82.45 \%)$ as compared to that observed in our study[6]. Further, majority of our patients $(46 \%)$ were unaware that diabetes could be hereditary, which is in consensus with the finding $(42.02 \%)$ reported by Shah et al. in their KAP study on type 2 diabetes patients in the Saurashtra region of Gujarat [7]. However, Rathod et al. finding differed greatly because only $8.78 \%$ of their study subjects were unaware of the same [6]. Additionally, $45 \%$ and $38 \%$ of our patients were unaware of the eye and kidney complications related to diabetes, respectively.

Some subjects $(30 \%)$ thought that they could stop taking medication once their blood sugar level normalized. Considering these findings, it is evident that there is a need to provide information related to these factors in future diabetes awareness programs. 


\section{Original Research Article}

On the brighter side, all our patients $(100 \%)$ were aware that they were suffering from diabetes and approximately all of them (99\%) were aware of dietary restrictions related to carbohydrates. A very high percentage of our patients (97\%) knew about hypoglycaemia and its symptoms. Although a substantial proportion of our sample patients (86\%) believed that exercising can be beneficial for diabetics, the same was considerably higher in the study by Rathod et al. (98.24\%) [6]. In the current study, only $16 \%$ of the patients were unaware that diabetes cannot be permanently cured, which was lower than that found in the study by Shah et al. (38.23\%)[7]. A significant percentage of the subjects of the current study (70\%) were conscious of obesity as a risk factor for diabetes.

The overall attitudes of majority of the patients in the present study (64\%) were good. Further, a substantial proportion of our participants $(94 \%)$ believed in following a controlled diet and $98 \%$ of them thought regular blood glucose monitoring was important. However, over $50 \%$ of the patients had a negative attitude towards exercising and $31 \%$ of them were not willing to take medicines on regular basis, which are a cause of concern and these areas need to be highlighted in diabetes education programs. When these results were compared to similar studies conducted by other authors (e.g., Bollu et al. and Rathod et al.) inconsistencies were observed [6,11]. Specifically, Bollu et al.reported that only $36 \%$ of their sampled patients had a good attitude towards exercise, and only $24 \%$ were able to follow a controlled diet [11]. In another study by Rathod et al.,73.68\% of the individuals had a positive attitude towards exercise and only around $35 \%$ of them were willing to follow a controlled and planned diet [6].

In the context of practice, only $31 \%$ of our patients scored above the average level, but it was encouraging to note that a very high proportion of our patients (98\%) visited the doctor regularly and took the medicines as prescribed. In our study, only $19 \%$ of the respondents owned a glucometer; however, $72 \%$ of the subjects reported that they checked their blood sugar at least once a month. These results were very similar to those reported in the study by Shah et al., wherein only $10.08 \%$ of the patients possessed a glucometer and $70.16 \%$ monitored their blood glucose level regularly [7]. Majority of our patients consumed fruits (74\%) and green leafy vegetables $(95 \%)$ regularly, whereas significantly lower figures were reported in the study by Shah et al., with only $31.93 \%$ and $54.21 \%$ of the patients reporting the inclusion of green leafy vegetables and fruits in their daily diet, respectively [7]. In the present work, it was found that $55 \%$ of the respondents monitored their feet daily for any wound or injury, which was in consensus with the finding of $56 \%$ reported by Shah et al. [7]. A considerably low proportion of our subjects $(41 \%)$ went for eye checkups every six months. Hence, it is necessary to provide health education on eye complications of diabetes, to prevent diabetes-associated blindness.

In the present study, $55 \%$ and $43 \%$ of the patients had average or good KAP scores, respectively, which is a satisfactory finding. Furthermore, education, occupation, and socioeconomic status were found to influence the overall KAP score of the patients. Other authors (e.g., Shah et al., Al Bhimani et al.,and AlMaskari et al.,) have also found a close association between literacy and KAP scores [7,10,12]. Thus, results show beyond doubt that literacy is an important factor which affects the knowledge, attitudes and practices of the population.

\section{Conclusion}

KAP studies are necessary for designing efficacious awareness and disease control programs. Diabetes is associated with high morbidity and mortality. Here, the onus is on the patients to control their disease, and merely knowing about the diagnosis is not enough. Hence, proper health education and individual counseling should be practiced in various healthcare setups to ensure that each patient with diabetes has sufficient information and that they are motivated to lead a better life. Although our study provides important baseline data, it is associated with limitations such as the limited sample size, the inclusion of inpatients alone, and the incorporation of a single study Centre. To provide sound health care, further related research should be conducted, preferably on a larger scale, to compare the changes in perceptions of the population.

What this study adds to the existing knowledge? Our study shows that irrespective of the age and gender of the subjects, there is a clear association of occupation and socioeconomic status with diabetes awareness and self-care. This depicts that awareness programs donot reach the less privileged sections of the society althoughthey need to be educated on the matters related to health as much as the elite.

\section{Contribution of authors}

- Contribution to the conception and design-Author 4

- Contribution to the acquisition of data - Author 1 


\section{Original Research Article}

- Contribution to the analysis and interpretation of data - Author 2

- Contribution to the drafting of the article - Author 1

- Contribution to critically revising the article Author 3

- Contribution to final approval of the version to be published - Author 2

Acknowledgements: Authors are thankful to the Dean, Dr. R.R. Wavare of Sri Aurobindo Medical College and Postgraduate Institute, Dr. R.K. Jha, Professor and Head of the Department of General Medicine, Sri Aurobindo Medical College and Postgraduate Institute for their support during the study. The authors are also deeply grateful to all the patients who were the core of their study and without them this study would not be possible.

Financialsupport:The cost of the study was completely borne by the researchers. As this was a survey, no additional test/procedure or investigation was conducted as a part of the study. Hence, there was no financial burden on the patient or on the institution.

\section{Funding: Nil, Conflict of interest: None. \\ Permission of IRB: Yes}

\section{References}

1. Trplitt LC, Reasner AC, Isley LW, DiPiro JT, Talbert RL. Diabetes mellitus. In: Dipiro JT, Talbert RC, Matzke GR, Wells BG, Rosey LM, editors. Pharmacotherapy pathophysiologic approach. 7th ed. New York: Mc Graw Hill; 2005. pp. 1333-67.

2. Shaw JE, Sicree RA, Zimmet PZ. Global estimates of the prevalence of diabetes for 2010 and 2030. Diabetes Res Clin Pract. 2010 Jan;87(1):4-14. doi: 10.1016/j. diabres. 2009.10.007. Epub 2009 Nov 6.

3. Joshi SR, Parikh RM. India--diabetescapital of the world: no wheading to wardshypertension. J Assoc Physicians India. 2007 May;55:323-4.

4. Yesudian CA, Grepstad M, Visintin E, Ferrario A. The economic burden of diabetes in India: a review of the literature. Global Health. 2014 Dec 2;10:80. doi: 10. 1186/s12992-014-0080-x.
5. World Health Organization. Diabetes mellitus [article on the internet], [Place unknown]: World Health Organization; 2010 [cited 2016 Dec 11]. Available from: http:// www. who. int/ mediacentre/ factsheets/ fs138/en/.

6. Rathod GB, Rathod S, Parmar P, Parikh A. Study of knowledge, attitude and practice of general population of Waghodia towards Diabetes mellitus. Int JCurRes Rev 2014;6(1):63-8.

7. Shah VN, Kamdar PK, Shah N. Assessing the knowledge, attitudes and practice of type 2 diabetes among patients of Saurashtra region, Gujarat. Int J Diabetes Dev Ctries. 2009 Jul;29(3):118-22. doi: 10. 4103/ 0973-3930.54288.

8. Mohan D, Raj D, Shanthirani CS, Datta M, Unwin NC, Kapur A, Mohan V. Awareness and knowledge of diabetes in Chennai--the Chennai Urban Rural Epidemiology Study [CURES-9]. J Assoc Physicians India. 2005 Apr;53:283-7.

9. Islam FM, Chakrabarti R, Dirani M, Islam MT, Ormsby G, Wahab M, Critchley C, Finger RP. Knowledge, attitudes and practice of diabetes in rural Bangladesh: the Bangladesh Population based Diabetes and Eye Study (BPDES). PLoS One. 2014 Oct 14;9 (10): e110368. doi: 10.1371/journal.pone.0110368. e Collection 2014.

10. Al Bimani ZS, Khan SA, David P. Evaluation of T2DM related knowledge and practices of Omani patients. Saudi Pharm J. 2015 Jan;23(1):22-7. doi: 10. 1016/j. jsps.2013.12.006. Epub 2013 Dec 22.

11. Bollu M, Koushik K, Surya Prakash A, et al.Study of knowledge, attitude, and practice of general population of Guntur toward silent killer diseases: hypertension and diabetes.Asian J Pharm Clin Res 2015; 8(4):74-8.

12. Al-Maskari F, El-Sadig M, Al-Kaabi JM, Afandi B, Nagelkerke N, Yeatts KB. Knowledge, attitude and practices of diabetic patients in the United Arab Emirates. PLoS One. 2013; 8 (1):e52857. doi: 10.1371/ journal. pone.0052857. Epub 2013 Jan 14.

\section{How to cite this article?}

Tejaswi P, Dhakre S, Reddy P, Goyal C. Evaluation of the knowledge, attitudes and practices of diabetic patients in a tertiary care hospital in Central India. Int J Med Res Rev 2018;6(01):24-32. doi:10.17511/ijmrr. 2018.i01.05. 